\title{
Studying the Implementation of Public Programs
}

Robert K. Yin

Visiting Associate Professor

Department of Urban Studies and Planning

Massachusetts Institute of Technology
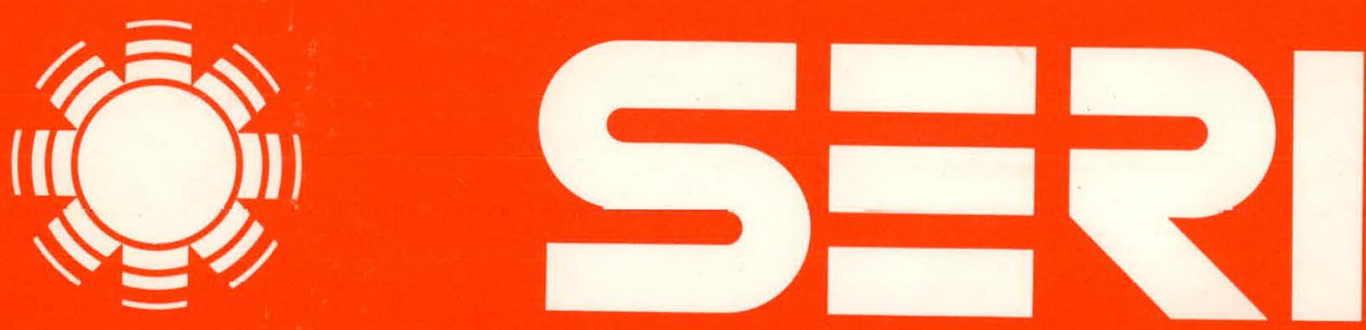

Solar Energy Research Institute

A Division of Midwest Research Institute

1617 Cole Boulevard

Golden, Colorado 80401

Operated for the

U.S. Department of Energy

under Contract No. EG-77-C-01-4042 


\section{DISCLAIMER}

This report was prepared as an account of work sponsored by an agency of the United States Government. Neither the United States Government nor any agency Thereof, nor any of their employees, makes any warranty, express or implied, or assumes any legal liability or responsibility for the accuracy, completeness, or usefulness of any information, apparatus, product, or process disclosed, or represents that its use would not infringe privately owned rights. Reference herein to any specific commercial product, process, or service by trade name, trademark, manufacturer, or otherwise does not necessarily constitute or imply its endorsement, recommendation, or favoring by the United States Government or any agency thereof. The views and opinions of authors expressed herein do not necessarily state or reflect those of the United States Government or any agency thereof. 


\section{DISCLAIMER}

Portions of this document may be illegible in electronic image products. Images are produced from the best available original document. 
Printed in the United States of America Available from:

National Technical Information Service

U.S. Department of Commerce

5285 Port Royal Road

Springfield, VA 22161

Price:

Microfiche $\$ 3.00$

Printed Copy $\$ 4.50$

\begin{abstract}
NOTICE
This report was prepared as an account of work sponsored by the United States Government. Neither the United States nor the United States Department of Energy, nor any of their employees, nor any of their contractors, subcontractors, or their employees, makes any warranty, express or implied, or assumes any legal liability or responsibility for the accuracy, completeness or usefulness of any information, apparatus, product or process disclosed, or represents that its use would not infringe privately owned rights.
\end{abstract}


SERI $/ T R-352-577$

UC CATEGORY: UC-58b

STUDYING THE IMPLEMENTATION

OF PUBLIC PROGRAMS

ROBERT K. YIN

VISITING ASSOCIATE PROFESSOR

DEPARTMENT OF URBAN STUDIES AND

PLANN.ING

MASSACHUSETTS INSTITUTE, OF TECHNOLOGY

JANUARY 1980

DISCLAIMER

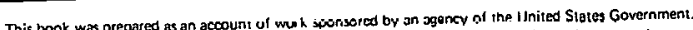

This book was pres $\mathrm{S}$ as Government nor any agency thereof. nor any of their emplovees. makes any

Nartranty, express or implied, or assumes any legal liabilitity or responsibility for the sccuracy.

complateness, or usefulness of any information, apparatus. product. or process disclosed. Of

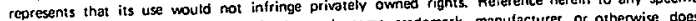

commercial product, process, of service by itsde nast.

not necessarily constiute or imply is and

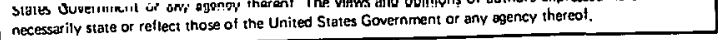

PREPARED UNDER TASK NO. 5633.98

\section{Solar Energy Research Institute}

1536 Cole Boulevard

Golden, Colorado 80401

A Division of Midwest Research Institute

Prepared for the

U.S. Department of Energy

Contract No. EG. $77 \cdot C \cdot 01 \cdot 4042$ 
THIS PAGE

\section{WAS INTENTIONALLY LEFT BLANK}


SEP

TR -577

FOREWORD

This report was prepared as part of a series of studies conducted by SERI of solar incentives introduced by state governments. The second in the series of studies focused on the implementation of state solar incentives -the processes by which solar laws are translated into functioning incentive programs. A number of fundamental issues in data collection, analysis and validation arose early in the project that were likely to confront subsequent SERI studies of organizational and public policy-making processes, and it was decided that a critical assessment of approaches employed to study the implementation of public programs was needed. Dr. Robert Yin agreed to undertake the task, and this is his report. The report was prepared under the auspices of the Policy Analysis Branch, Analysis Division; administrative responsibilities were carried out by J. David Roessner.

Approved for:

SOLAR ENERGY RESEARCH INSTITUTE

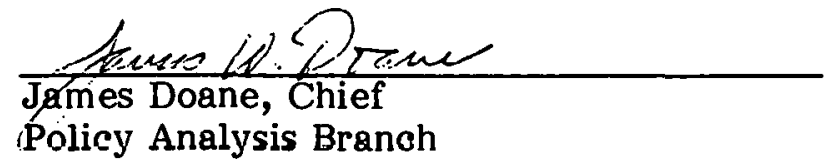

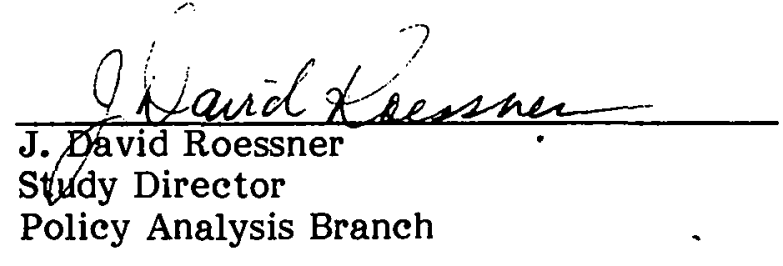

iii 
THIS PAGE

WAS INTENTIONALLY

LEFT BLANK 


\section{SUMMARY}

This report describes and critically assesses approaches that have been employed to study the implementation of public programs. Implementation is defined as the process by which new policies and/or practices are installed in organizations. The report was produced because of the increased interest among researchers and policy makers alike in the linkages between policy and outcome. The study of implementation has barely begun, and it was recognized that methodological issues of a particularly complex nature arise because of certain unique characteristics of implementation processes:

- they involve a series of decisions that occur over a long period of time, with no clear beginning or end points;

- their outcomes have direct or indirect implications that are too complex for single-factor theories;

- they involve a large number of participants; and

- they involve situations that are rather unique in terms of agency context, historical moment in time, and other key elements.

The approach employed in the report was to examine the methods that have been used in a number of "exemplary" studies of implementation. These studies are commonly cited in publications and informally in research circles. Descriptive material from each study was used to address three questions:

1. How is evidence collected in studies of implementation?

2. How is evidence analyzed?

3. What are the reasons for believing the conclusions from such studies?

The report concludes with recommendations for the conduct of future studies of implementation. 


\section{THIS PAGE}

\section{WAS INTENTIONALLY LEFT BLANK}


TABLE OF CONTENTS

Page

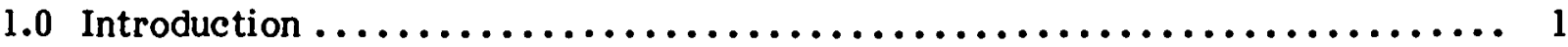

1.1 The Interaction of Methods and Concepts $\ldots \ldots \ldots \ldots \ldots \ldots \ldots \ldots \ldots$

1.2 An Exemplary Studies Approach .......................... 3

1.2.1 Identification of Exemplary Studies ................... 3

1.2.2 Topics to be Reviewed .......................... 6

2.0 How Evidence is Collected in Studies of Implementation .............. 11

2.1 Unstructured Discussions . .......................... 11

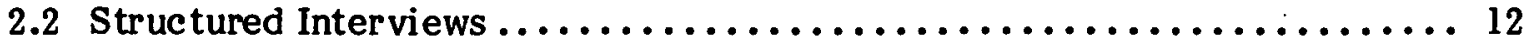

2.3 Docum ents and News Reports $\ldots \ldots \ldots \ldots \ldots \ldots \ldots \ldots \ldots \ldots \ldots \ldots \ldots \ldots$

2.4 Participant-Observation............................. 14

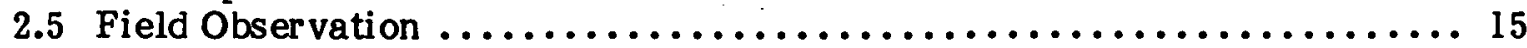

2.6 Citation of Participants' Published Reports ................... 16

2.7 Use of Multiple Sources of Evidence ..................... 16

3.0 How Evidence is Analyzed in Studies of Implementation . . . . . . . . . . . 19

3.1 Preanalysis ......................................... 19

3.2 Piecing Together the "Facts" of the Implementation Experience ....... 20

3.3 Merging Evidence from Various Sources .................... 21

3.4 Aggregating Experiences from More than a Single Site ............. 23

3.5 Testing Alternative Explanations ....................... 24

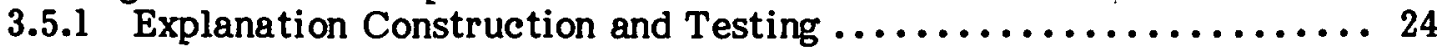

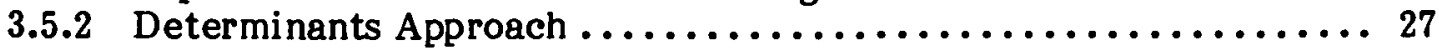

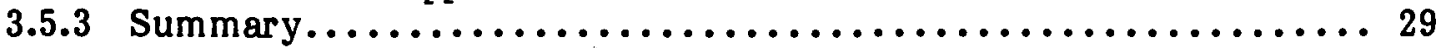

4.0 Reasons for Believing the Conclusions of Implementation Studies ......... 31

4.1 Formal Methodological Discussions ...................... 31

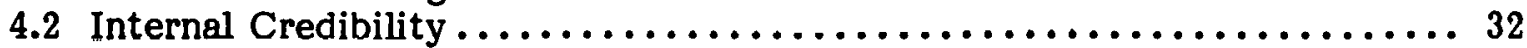

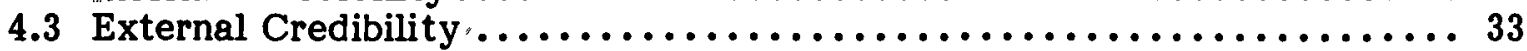

4.4 Concluding Comments ............................ 34

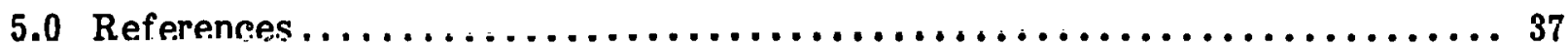


THIS PAGE

WAS INTENTIONALLY

LEFT BLANK 


\section{LIST OF TABLES}

$\underline{\text { Page }}$

1-1 Sample of Exemplary Studies of Implem entation $\ldots \ldots \ldots \ldots \ldots \ldots \ldots \ldots \ldots \ldots$

1-2 Summaries of 11 Exemplary Studies...................... 7

3-1 Illustrative Chronology from 1 Year of Nelkin (1973) Study . . . . . . . . . . . 22

3-2 Mlustrative Tabulation of Multiple Sites from Baer et al. (1976) . . . . . . . . 25 


\section{SECTION 1.0}

\section{INTRODUCTION}

\subsection{THE INTERACTION OP METHODS AND CONCEPTS}

The natural and social sciences are replete with examples where methodological and conceptual advances have been intertwined. For instance, the development of microelectrodes in biology in the late 1950s gave researchers the ability to record signals from single nerve cells, and thereby to develop new insights into brain function. Similarly, the evolution of quantitative historical techniques during the last 10 years has allowed social historians to construct new and more insightful portraits of life in early American cities. Finally, the continued refinement of survey research techniques, whether for the national census, for political polling, or for studies of criminal victimization, has provided fresh sources of information for theories about American social behavior.

A general proposition from these and numerous other examples is that advances in scientific knowledge depend both on purely conceptual breakthroughs and on improvements in the craft, or methods, available for inquiry. Moreover, this relationship between concept and craft appears to emerge most vigorously when a broad new topic of research is beginning to be explored. Typically, a new set of problems or theories leads to the need for new empirical information; the theoretical propositions may deviate from the normative science of the day, leading to the need for innovative or refined methods; and the methodological improvements and subsequent evidence of ten yield yet newer conceptual insights. The process is iterative, incremental, and symbiotic.

Implementation, or the installation of new policies/practices in public and private organizations, has become one such research topic. Not more than 5 or 10 years ago, there was a truly meager amount of research on implementation (Pressman and wildavsky 1973; Hargrove 1975; Williams 1976). This situation existed in spite of the fact that many new public programs were being implemented-e.g., those initiated in the 1960 s as part of the Great Society (Levitan and Taggart 1976) or of municipal reform (Yin and Yates 1975). Little knowledge was available to assist in the implementation process, and only a few observers even appreciated the need to understand why implementation failed or succeeded.

At the present time, interest in implementation has burgeoned (Berman 1978). In fact, the interest reflects a larger theme, which has to do with the study of public policy making and organizational innovation more generally. Greenberg et al. (1977) have suggested the parameters of the overall process; whether under the guise of implementation, public policy making, or organizational innovation, all involve:

- a series of decisions that occur over a long period of time, with no clear beginning or end points;

- outcomes whose direct and indirect implications are too complex for singlefactor theories;

- a large number of relevant participants; and

- situations that are rather special in terms of agency context, historical moment in time, and other key elements. 
Given these parameters, however, implementation and related organizational processes are likely to be difficult subjects of study.

Not surprisingly, the relationship between concept and craft has already become evident in several recent works. Investigators who have attempted to clarify current issues concerning organizational innovation, for instance, have ended their discussions with suggestions for methodological improvements. One highly regarded article by George Downs and Larry Mohr (1976) is, in fact, titled "Conceptual Issues in the Study of Innovation," yet concludes with seven methodological prescriptions rather than any conceptual propositions (emphasis mine). In a similar vein, Everett Rogers has repeatedly pleaded the case for breaking away from cross-sectional analyses and one-shot surveys as the first step in appreciating the conceptual distinction between the traditional study of diffusion and the newer study of organizational innovation, which requires the ability to trace organizational processes over time (Kogers 1975; Rogers with Fvelumu 1975; Rogers and Agarwala-Rogers 1976). Other discussions havc focuscd on more specialized asperts of organizational innovation but have nevertheless also emphasized methodological lessons-e.g., intergovermintal innovation, in which federál initlatives are used to spur state or local governments into action (Williams 1976; Bardach 1977), and innovation due to the provision of technical information to public agencies (Sabatier 1978). In fact, in the last mentioned example, Sabatier paradoxically ends his substantive discussion with a section on "implications for future research" that contains only methodological suggestions and not a hint of a substantive framework or theoretical proposition.

These examples show, however, that the concerns with craft knowledge have tended to follow only indirectly from substantive discussions. In contrast, the present paper deals directly with the interaction between concept and craft, with the purpose of improving the craft with which implementation-and organizational innovation and public policy making processes more generally-is studied. The need for such a direct inquiry is based on the fact that many investigators are initiating new studies of implementation. For instance, the Solar Energy Research Institute has initiated a series of projects to examine the factors affecting the successful implementation of solar energy programs (Roessner et al. 1979). The investigators wisely view implementation as a key issue, noting that success will probably be influenced as much by the way the programs were implemented as by their original design. Yet, without explicit methodological guidance, such researchers will have to be careful to avoid either of two pitfalls. First, inappropriate methods of inquiry may be negligently used. Second, investigators may struggle de novo with methods that have already been refined by others. Overall, the methods for studying implementation are in need of better description, and the present paper is viewed as one step in this direction.

Naturally, it should also be pointed out that, becuuse of the symbiotic relationship between concept and craft, any improvements in craft knowledge may also have implications for knowledge about substance. In part, this is reflected by the continuing problem that inquiries into method cannot be completely devoid of conceptual bias, an observation that has been carefully noted by those who have dealt with the different "conceptual lenses" imposed by different models of organizational behavior (e.g. Allison 1971; Elmore 1978). Often, the very measures that an investigator considers appropriate-on the surface, a methodological concern-may be a function of conceptual blinders and an implicit substantive model. This report will attempt to avoid some of these pitfalls by limiting itself to a few simple questions, which serve as the organizing themes for the bulk of the text:

- How is evidence collected in studies of implementation? 
- How is evidence analyzed?

- What are the reasons for believing the conclusions from such studies?

\subsection{AN EXEMPLARY STUDIES APPROACH}

There are several ways of addressing these questions:

- First, one could attempt to generalize about the methodological implications from one's own research (e.g., Reiss 1971; Iannacone 1975). However, such an approach fails to give the reader confidence that the methodogical lessons, because they have been drawn from a narrow experimental base, are necessarily applicable to the whole range of implementation issues.

- Second, one could review existing studies of implementation in a strictly tabular fashion, much like previous "evaluations of evaluations" (e.g., Bernstein and Freeman 1975; Yin et al. 1976). This is an unrealistic alternative because of the small number of implementation studies.

- Third, one could create a catalog or inventory of research methods, systematically indicating the advantages or disadvantages of each, under different conditions (e.g., Barnes 1971; Weick 1968; Douds and Rubenstein 1975). However, these inventories also pose a problem in that they do not yield sharp insights into the methodological choices that must be made; one inventory, for instance, does not even arrive at any overall conclusions (Douds and Rubenstein 1975).

- Fourth, one could take an advocate position with regard to certain methodologies (e.g., Eckstein 1975; Stake 1978). However, the taking of such normative positions would appear to be premature at this time.

Yet a fif th approach may overcome some of the shortcomings of these four approaches, and it is the one that has been pursued here. The approach is to examine the methods that have been used in a number of exemplary studies, defined as studies that are commonly cited, in publications and conversations, by other researchers. The analysis of such st udies can yield empirical information on craft knowledge, allowing the reader to judge independently the state of the art. Moreover, although there have been few exemplary studies of implementation, those that have been published do include works authored by some highly esteemed investigators and do cover a range of different service sectors. To this extent, the reader may gain some confidence about the validity and generalizability of the lessons to be learned.

\subsubsection{Identification of Exemplary Studies}

Exemplary studies of implementation were identified by noting those books or articles that have appeared in published form, and were hence subjected to some type of peer review. In each case, the study had to deal with an actual implementation experiencei.e., the initiation of a new practice within a local setting, regardless of whether the new practice was part of a federally instigated program or not. Studies and review articles containing no original empirical information were not considered.

A preliminary review revealed that the relevant works fell into two categories, the first dealing with studies of implementation experiences at single sites (single-site studies), and the second dealing with the lessons learned from experiences at more than one site 
(multiple-site studies). The latter category could be further divided into those studies covering only a single type of local service and those studies simultaneously covering a variety of services. Thus, three pools of potential studies were identified, and an atte mpt was made to cover a variety of service topics in each pool.

The results of a citation search and discussions with colleagues are shown in Table 1-1, which identifies 11 exemplary studies. Of these 11 , four were single-site cases, distributed among several local services (community or economic development, education, general municipal services, and health). Another four were multiple-site studies, each limited to a single type of local service that partially matched the single-site studies, and the last three were multiple-site studies in which each investigation itself covered $a$ variety of services.

Tahle 1-1. SAMPLE OF EXEMPLARY STUDIES OF IMPLEMENTATION

\begin{tabular}{|c|c|c|}
\hline \multirow[b]{2}{*}{ Service Sector } & \multicolumn{2}{|c|}{ Type of Study } \\
\hline & Single-Site & Multiple-Site \\
\hline $\begin{array}{l}\text { Community and } \\
\text { Economic Development }\end{array}$ & $\begin{array}{l}\text { 1. Pressman and Wildavsky, } \\
1973\end{array}$ & 5. Derthick, 1972 \\
\hline Education & 2. Gross et al., 1971 & $\begin{array}{l}\text { 6. Berman and MeLaughlin, } \\
1974-78^{*}\end{array}$ \\
\hline $\begin{array}{l}\text { General Municipal } \\
\text { Services (sanitation } \\
\text { and fire) }\end{array}$ & 3. Mechling, 1974 & 7. Walker, 1978* \\
\hline Health & 4. Nelkin, 1973 & 8. Attewell and Gerstein, 1979 \\
\hline $\begin{array}{l}\text { Multiple Service } \\
\text { Sectors within } \\
\text { Same Study }\end{array}$ & & $\begin{array}{l}\text { 9. Baer et al., } 1976^{*} \\
\text { 10. Lambright, } 1977^{*} \\
\text { 11. Yin, } 1979\end{array}$ \\
\hline
\end{tabular}

*This reference is to the full study, which appeared in report form; related articles, however, were publishted in academic journals in each oase (see McLaughlin, 1976; Berman and McLaughlin, 1976; Berman, 1978; Walker, 1975; Baer et al., 1977; and Lambright and Flynn, 1977). 
A few words should be said about the studies that were considered but not included in the final sample.* These fell into the following categories:

- single- or multiple-site studies of new service practices that mainly focused on the adoption rather than implementation process (e.g., Mytinger 1968; Feller et al. 1974; Corwin 1975; Nelson and Sieber 1976; Bingham 1976; Feller et al. 1976; Daft and Becker 1978);

- multiple-site studies of implementation, but which only reported aggregate findings without explicit publication of or reference to the component individual site experiences (e.g., Murphy 1971; Murphy 1973; Downs 1976);**

- studies that had either no published version (even in article form) or whose only available version was too skimpy to provide enough material for analysis (e.g., Banfield 1973; Eveland et al. 1977; and the various articles in Nelson and Yates 1978); and

- studies whose primary concern was only with implementation at the federal level, and in which either no local agency was involved (e.g., Maxmanian and Nienaber 1979) or the inquiry was directed at the politics and bureaucracy of federal agencies (e.g., Elmore 1975; and the articles that appear in Williams and Elmore 1976).

The final sample was thus a rather exclusive collection, and it is open to challenge on the basis of nonrepresentativeness and bias. However, note that the goal was not to conduct an exhaustive review of works representing the field at large. Instead, the goal was to identify the best examples of implementation studies, and to determine the methodological lessons from this elite group, in the hope of improving our craft knowledge.*** Each of the 11 studies is summarized in Table 1-2. In terms of external validity, the studies do cover a variety of services, technological and programmatic innovations, and sites across the country.

*One study that was seriously considered for inclusion was Bardach (1977). However, the main contributions of this book are to the development of implementation theory, and the book only reports on its own empirical study in a fragmentary manner. Another study that actually could have been included was nevertheless considered redundant with the Mechling (1974) study, which was one of the 11 selected. This was a study of a police manpower allocation innovation (Moore et al. 1974), taking place at a similar time and with similar actors to those in the Mechling study, and using similar methods.

**Even though the primary interest may have been cross-site conclusions, this constraint was necessary to facilitate judgments regarding the type of evidence used by the investigator.

*** One review of an ostensibly larger number of studies, though limited to the field of education, is an article by Fullan and Pomfret (1977). This article identified 15 studies of educational implementation, but a closer examination reveals that most of the studies were conference papers, theses, and other consultant reports that often contain imcomplete results and are unreviewed by referees or colleagues. In addition, at least one study was about an implementation experience in the United Kingdom, which would see $m$ to have a dubious relevance to the problems of American governance. Because of the disparate nature of the collected works, the applicability of the aggregate conclusions is unclear. 


\subsubsection{Topics to be Reviewed}

As noted earlier, the methodological lessons from these studies were organized according to three questions: (1) how evidence is collected, (2) how evidence is analyzed, and (3) the reasons for believing the conclusions from such studies. These questions are different from those that have previously been used in reviewing empirical studies. Most "evaluations of evaluations," for instance, examine the measures used, the research design used, and research utilization-i.e., the degree to which an evaluation study has addressed decision-making issues and has provided relevant findings in a timely manner.*

The different emphasis in the present paper was related to a dcsire not to impose, beforehand, a particular paradigm on implementation or related organizational research. Thus, the three selected questions ure legitimate concerns rcgardless of whether an empirical effort falls into the standard experimental and quasi-experimentul paradigm, into historical or economic analysis, or even into journalistic or legal approaches. In all of these situations, as long as conclusioñs are belng druwn un the busis of empirical observations, the three questions would seem to be applicable. In contrast, questions about the use of research measures and design derived from a narrower orientation-i.e., behavioral and biological science (Nachmias 1978; Yin 1977a, 1978). Although these methodological issues may be relevant to evaluation research, their imposition on the study of implementation (as well as on investigations of related organizational processes) appears premature.

*See Yin et al. (1976) for a discussion of the various approaches used in secondary analyses or "evaluations" of evaluation studies. 
Table 1-2. SUMMARIES OF 11 EXEMPLARY STUDIES

\section{A. SINGLE-SITE STUDIES}

1. Pressman and Wildavsky (1973): A study of an attempt by the U.S. Economic Development Administration to implement a special project in Oakland, Calif. The case study covers the experiences from 1965 to 1971 , describing the several public works components of the project. The study stresses the complexity of the implementation process in terms of the number of participants, decisions, and agreements involved. The study notes the disappointing results-only a couple hundred jobs out of a promised 3000 were produced-and the reasons for this outcome.

2. Gross et al. (1971): A study of changes in one New England school during a school year in the late 1960s. The innovation called for teachers to follow a "catalytic role model'L-where they organized classroom activities according to students' interests and with emphasis on the learning process rather than content. The case was deliberately chosen because teachers were change-oriented at the outset of the innovation, but implementation failed in spite of this low "resistance to change." The case study describes the low degree of implementation and analyzes the reasons for failure.

3. Mechling (1974): A study of a new manpower scheduling system, implemented in New York City's Department of Sanitation. The new scheduling system called for a closer match between the daily work force and the daily work load, throughout any given week. The innovation was initially conceived in 1968 and was put into full operation by 1972. The case study calls attention to the role of analysts as change agents and traces the detailed implementation process which, while successful, was nevertheless complex and extended over a long period of time.

4. Nelkin (1973): A study of a methadone maintenance program, initiated in an upper New York state community in 1971. The case focuses on the local conditions that led to the need for such a program, on the problems of integrating the program with an existing psychiatric clinic, and on the ultimate role conflicts between the staff and clients of the program. In spite of these problems, the program was implemented, with 14 of 51 of the clients in the program being employed a year later. 'The study focuses, however, both on the reasons why the program has not been more successful and why a large number of such programs has not been initiated across the country. 
Table 1-2. SUMMARIES OF 11 EXEMPLARY STUDIES (continued)

B. MULTIPLE-SITE STUDIES

(Each study covers a single service sector)

5. Derthick (1972): A multiple-site study of seven projects in a federal community development program (New Towns in-Town) with the projects located in Washington, D.C.; Louisville, Ky.; Atlanta, Ga.; an area outside of Detroit, Mich.; San Antonio, Tex.; New Bedford, Mass.; and San Francisco, Calif. The study traces the progress at each site, covering the period from 1967 to 1971 , as well as the events at the fcderal level that led to the design of the program. The main idea was to make federal surplus lands available to cities, for the development of luw-incume housing. Except for two sites-at which only 300 housing units were built or under construction-the projects failed to be implemented.

6. Berman and McLaughlin (1974-1978): A study of 293 federally funded education projects, mainly initiated at the end of the 1960s. Each project was designed to change some classroom practice at the elementary or secondary level, with a focus on bilingual projects, exemplary programs, right-to-read programs, or innovation practices more generally. The study, itself reported in several separate volumes over a period of years, consisted of a survey of officials associated with the 293 projects (over 3000 respondents were interviewed in two waves) as well as 29 case studies of a subset of the projects. It was found that few of the projects were continued after the 3- to 5-year period of federal funding. More important, however, the study articulates the implementation process and identifies this process (rather than the nature of the innovation or other factors) as a prime determinant of any continuation outcome.

7. Walker (1978): Five case studies of the implementation of new manpower allocation policies in urban fire departments: Wilmingtur, Del.; Trenton, N.J.; Yonkcrs, N.Y.s Jersey City, N.J.; and Denver, Culo. In each case, a new allocation plan was based on a detailed analysis of existing deployment patterns and the use of mathematical models to determine various options, with increased manpower productivity the main goal. The study describes the events in each of the five sites from about 1973 to 1977, with some sites accomplishing successful implementation and others not. The study identifies several overall reasons for Implem entation out comes.

8. Attewell arid Gerstein (1970) $\Lambda$ study of the general disappointment with methadone maintenance programs at the local level. The implementation problem is analyzed in terms of organizational theory, noting that federal regulations and other constraints forced local clinics away from therapeutic aims and created role conflicts within the operation of the clinics. As a result, organizational control was difficult to maintain, and the clinics operated less successfully than originally envisaged. 
Table 1-2. SUMMARIES OF 11 EXEMPLARY STUDIES (concluded)

\author{
C. MULTIPLE-SITE STUDIES
}

(Each study covers different services)

9. Baer et al. (1976): A study of 24 major demonstration projects, all aimed at testing new technologies for private- or public-sector use. The cases include such undertakings as Operation Breakthrough (modular housing), the nuclear ship Savannah, the Connecticut Yankee power reactor, a mechanized garbage collection truck, the Morgantown (W.V.) personal rapid transit system, computer-assisted electrocardiogram analysis, an expressway surveillance and control project, and other projects mainly started throughout the 1960s. Some of the projects were successfully implemented, whereas others were not. Individual case studies are used to describe the implementation experiences for each project; an aggregate analysis identifies the factors associated with successfully implemented demonstration projects.

10. Lambright (1977): A study of 20 innovations in two cities-Syracuse, N.Y., and Rochester, N.Y. The innovations were mainly attempted from the mid-1960s to the mid-1970s and cover a variety of urban services (fire, police, urban development, education, and a smattering of others) as well as "hard" and "sof t" technologies (e.g., a campus plan, a minipumper, a crime control team, a dial-a-bus system, cable television, a solid waste shredding machine, and a school resources and information program). A few of the innovations were not adopted after serious initial consideration; for the others, the study examines the organizational and political changes that occurred as the innovations came into use and as some became standard practice.

11. Yin (1979): A study of the implementation experiences with six types of innovations in different local services: police computers (police); computer-assisted instruction (education); closed-circuit television (education); mobile intensive care units (fire); breath testing for drunken driving (police); and an explosive device for penetrating barriers (fire). The experiences are reported as individual case studies for 19 sites, and an aggregate analysis also includes 90 other sites covered through telephone interviews. The study traces the organizational events that occur as a new practice becomes "standard" practice. These events, such as the transition from "soft" to "hard" money, the establishment of internal training routines, and survival over personnal turnover, are claimed to be similar, independent of the type of innovation or service. 


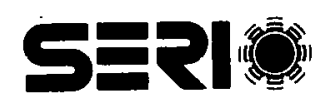




\section{SECTION 2.0}

\section{HOW EVIDENCE IS COLLECTED IN STUDIES OF IMPLEMENTATION}

The short answer here is that evidence is collected from numerous sources. The efforts are not unlike the work of the historian (e.g., Barzun and Graff 1977), except that the implem entation researcher, unlike the historian, also has access to contemporary informants. Thus, the implementation studies are marked by evidence from:

- unstructured discussions;

- structured interviews;

- documents and news reports;

- participant-observation by the research investigator;

- field observations; and

- citation of published reports written by one or more of the participants.

The following subsections describe the use of these different sources.

\subsection{UNSTRUCTURED DISCUSSIONS}

The most common source of data was based on unstructured "discussions" (the term "interview" does not seem warrranted), which are found in all 11 studies and which seem to play a critical role in the ultimate formulation of conclusions. Typically, field teams visited the site of the innovation and talked to an unstructured respondent pool in addition to using unstructured protocols. The results range from a quote by an unidentified respondent about the President of the United States:

"[The President] did not understand," one of his aids later said, "what a mixed blessing low-income housing was for the cities" (\#5, p. 84)*.

to a quote from an informal discussion with an unidentified teacher:

Williams [the innovator] has no classroom experience so he can't think it through; his philosophy is that it's an idea that the teacher has to work out (\#2, p. 151).

Both facts and opinions are derived from these discussions. Oftentimes, the information is not directly attributed to a specific discussion or respondent, though in most studies the names of the respondents are at least acknowledged (e.g., \#1, 7, and 11). Simply put, verbal reports by participants in the implementation process, whether directly quoted or not, appear to be a major source of evidence used in the exemplary studies.

*For simplicity's sake, the 11 studies have been numbered-in Table $1-1$ and will be cited in the remainder of this paper according to the appropriate number. 


\subsection{STRUCTURED INTERVIEWS}

The common use of information from unstructured discussions was not, however, accompanied by frequent use of structured interviews, represented by closed-ended questions and formal technology. An important finding is that in only one of the single-site studies (\#2) were such interviews used, and in only two of the multiple-site studies (\#6 and 11) were they used. (One suspects, however, that the survey method may be used more frequency in the less-than-exemplary implementation studies.) There are several potential reasons for this low frequency of use. First, structured interviews and surveys are costly to construct and conduct. Second, and more important, such interviews can only lead to verbal reports about phenomena that may really need to be assessed in other ways. For instance, Fullan and Pomfret (1977) puint out that when studies rely on "rcported use" as the measure of implementation,

The problem ... is not so much that people will deliberately deceive the researcher, but that it may only reflect an attitude of acceptance. (Emphasis in original text.)

Third, structured interviews are notoriously inefficient devices in substituting for the strength of unstructured discussions-i.e., the acquisition of "explanations" for an event or complex descriptions of a situation. In such instances, the use of a structured interview is inappropriate because an unstructured description is what is actually being solicited.

The possible mismatch between structured interviews and the study of implementation deserves further discussion because survey research is such a popular (and legitimate) craft that it may be inappropriately used in future studies of implementation. The strength of survey research is that it enables an investigator to construct an incidence report about behavior or attitudes. Thus, structured interviews can be used to show the percentage of respondents who own television sets, use a particular public service, or are satisfied with a particular innovation. To the extent that items such as practitioner or client satisfaction with an innovation are important in assessing implementation, the struc tured interview does play a critical role.

The technique tends to be less appropriate, however, where an implementation study is concerned with either describing or explaining the implementation process. Thus, in all three of the studies in which structured interviews were used (\#2,6, and 11), the evidence was not the only source of evidence about implementation. On the contrary, the structured interviews were used by all studies to complement field observations and to expand the number of sites or respondents covered by the study. In other words, the implementation process represents a complex interaction, over time, among a distinctive set of key actors and events at any given site; the sum of this complexity is more than the sum of the incidence reports typically created by a survey. In addition, whereas a second strength of the survey is to tap privately known behavior-e.g., attitudes or behavioral occurrences about which only the respondent knows-the key events in the implementation process may be more publicly accessible and hence better captured through other data collection procedures. 


\subsection{DOCUMENTS AND NEWS REPORTS}

As with unstructured discussions, each of the 11 studies took advantage of existing documents* and news reports as a source of evidence. The information from these external reports was not, however, collected by following any formal research procedure. None of the studies, for instance, indicated the extent of the documents that were available or the reasons for selecting the ones that were cited. In fact, the reader must give the authors the benefit of the doubt in assuming that the authors selected documents in an unbiased manner and interpreted the documents correctly. As an aid, one exemplary study (\#7) contains reproductions of numerous news articles, so the reader can reach his or her own judgment regarding the interpretive accuracy; similarly, one of the other studies (\#3) provides a reproduction of two key documents (agency memoranda).

The exemplary studies also varied in the degree to which specific documents were formally cited. At one extreme, the text of one study contains numerous direct quotations, and the reader is made aware, in the Acknowledgments section, that "except for a few interviews and some peripheral searches in other agencies, the HUD records are the major source for the ... analysis" (\#5, p. xi); nevertheless, the text actually has few footnotes, and the reader cannot attribute any individual piece of evidence to any specific document. A second study (\#4) exhibits similar problems. At the other extreme, the text of another study (\#1) contains numerous footnotes citing specific documents and news reports. In all, there appear to be few ground rules for current citation practice, and some standardization may be worth considering.

A more pertinent question for the present paper, however, is to ask what these documents revealed about the implementation process. First, the documents were a major source for identifying the dates, participants, and topics of key events. For example,

On December 9, 1965 [EDA of ficials] made their first visit to Oakland [and neglected visiting city hall] (\#l, p. 18).

On February 28, the Director of Public Safety formalized the decision in a memorandum to the Chief [the document is then reproduced in the text] (\# 7, p. 620).

These are the types of publicly knowable events that of ten characterize the implementation process. Second, the documents were used to provide interpretations of or reactions to key events. This interpretive function seems critical and is exemplified by the following:

In Louisville, in contrast to Atlanta, the local reception was poor. Where the Atlanta Constitution had welcomed Honor Farm as "fine opportunity," the Louisville Joumal was skeptical and sarcastic about Watterson Model Town (\#5, p. 58).

*There can be a wealth of documents available about organizations, including memoranda, agendas of meetings, in-house newsletters, records of scheduled activities, manuals, and other issuances. Where externally supported programs are involved, invaluable documents also include project proposals, evaluation studies, and internal reviews. 
As indicated in the news stories reproduced in Figs. 9.1 and 9.3, [the proposals met with a cool and hostile reception (\#7, p. 101).

In some cases, information from available documents was combined with information from unstructured discussions. Thus,

On October 5 the Oakland program suffered a severe jolt when Eugene

Foley announced his resignation as head of the EDA (\# 1, p. 31 ).

In this example, the "fact" of the resignation was announced in an internal agency document; the interpretation regarding the "severe jolt" and its implications came from the investigator's interview with Foley.

In summary, documents and news reports allow an investigator to trace both factual and interpretive information about the implementation process. The investigator can reconstruct, post hoc, the implementation experience from many different points of viewe.g., public reaction (as reflected in news accounts); participant reaction (as reflected in letters and other individually authored memoranda); and official reaction (as reflected in agency guidelines and issuances). A major lesson from this review of exemplary studies thus appears to be the need to plan for the use of documents in future studies of implementation. The documents not only provide a rich source of information, but also do tend to capture key aspects of the implementation process-e.g.., decisions, meetings, publicly stated priorities or positions, or other public actions. Where private motives or strategies are relevant, unstructured discussions may be used to complement the use of docum ents. But the information from both sources of evidence must be consistent with each other. In fact, consistency is such an important attribute that more shall be said about it later.

\subsection{PARTICIPANT OBEERVATION}

In only one exemplary study was the author a participant in the implementation experience (\#3).* "Participant" must be differentiated from "observer" in that the latter takes only a passive orientation regarding the course of events. A participant, in contrast, has a real role in the implementation process and must exercise it. (In the exemplary study being cited, the author was in actuality a major impetus behind the drive toward implementation.)

Although the opportunity for participant-observation in an implementation experience must be considered rare, the potential advantages and disadvantages of this source of evidence should be briefly reviewed. On the positive side, the participant-observer may be able to interpret key events in a manner that extends beyond the available documentary evidence. Consider the following example:

*In one other study (\#7) there is reason to believe that the author was also a participant during certain stages of the site experiences; however, this role is not explicit in the text of the study. In a third study (\#8, p. 312), the authors refer to their own previously published work in which they were participant-observers, but the evidence is not used directly in the exemplary study under review. 
DeLury had informally promised Elish that the union would go along with some version of the [proposed change]. A major scare came, however, when Kretschmer forgot and broke a personal commitment with DeLury not to publicly discuss the new system, ... The Times ran the [proposal] as a major story, ... and DeLury and Bigel were furious.

DeLury did not publicly deny his approval of the new system, however, and his private commitment held. Eventually his irritation with Kretschmer calmed down (\#3, p. 287).

Such a rendition of a critical event could only be pieced together by an informant who was present during the implementation experience; throughout this exemplary study, there are similar interpretations about the motives of key actors, the importance of external events and personnel turnover, and the strategies behind specific actions or policies.

On the negative side, the objectivity of the participant-observer can always be open to question. Even where events are not purposely being misconstrued, the participantobserver-by virtue of the participatory experience-may only recall events selectively or may arrive at an egocentric interpretation that is incorrect. Thus, to give the reader more confidence about such evidence, there should be ways that, at least in theory, the evidence can be confirmed. In the preceding quotation, for instance, the people's names that are referred to are real; in principle, one could have consulted both the Times story and the names persons to check the author's interpretation.*

\subsection{FIELD OBSERVATION}

Most but not all of the 11 exemplary studies made some direct observations of the implementation process in progress.** These observations were typically made during "site visits" for brief periods of time to at least a subset of the sites being studied. The observations were mainly of an informal nature, in which the investigators saw the activities associated with the implementation experience, e.g., organizational operations; the material artifacts of the innovation such as its hardware, training manuals, or products; and the actual use of the innovation in practice.

In two of the studies, the investigators were actually on the scene for extended periods, and the observations were formally tabulated; the tabulations later fulfilled an important part of the study. In the first study (\#2) the degree of implementation of an educational innovation was claimed to be reflected only by actual changes in practitioner roles and behavior. Thus, a key source of evidence for this study came from the use of observational protocols in individual classrooms; the amount of time spent in different roles by the classroom teacher was noted and tabulated (\#2, pp. 108-116). The results of these tabulations were interpreted by using other sources of evidence-e.g., unstructured discussions and formal interview data. However, the tabulations themselves stand as the

*For other examples of the ways that participation-observation can be improved as a methodology for conducting urban analysis, see Yin (1972).

** In the two major exceptions (\#l and 5), the studies were about innovations whose major activity had preceded the authors coming on the scene, and hence the studies actually assume a more historical orientation than the other nine. 
major source of evidence that implementation has not occurred to any great degree. In the other study (\#3) a major conclusion had to do with the role of analysts as "change agents." To support this conclusion the author estimated, from his own observations, the amount of time that analysts spend in performing "analytic" vs. "staff" vs. "change agent" roles. The final tabulation is presented in the text $(\# 3$, p. 303).

If an implementation experience is in progress as a study is being conducted, the use of field observations appears to provide information that is complementary to that found in documents or derived from discussions and interviews. As with participant-observation, the observations are a form of evidence that is not dependent upon verbal behavior; an investigator can get underneath the labels and concepts used in either documents or discussions and observe a phenomenon directly. Naturally, there are also potential problems. Most site visits, for instance, are scheduled for brief periods of time and on a casual basis; as a result, the operations or behavior being observed may not be representative of the site's normal activities. (Although it should also be pointed out that a site would have to go to considerable trouble to alter certain observable items, such as physical layouts of space and facilities, which may be important to the study.) In general, the more time that is spent at a site, the more confidence one can have in the observational results.

\subsection{CITATION OF PARTICIPAN'TS' PUBLISHED REPORTS}

A final manner in which evidence was collected was through publications written by participants in the implementation experience. This type of evidence was available and used extensively in one study (\#1), to help explain a motive or to provide information about reactions to key events. Similar evidence was also available in another study (\#8, p. 312), but was not cited as such or used in any specific place. None of the other 11 studies had occasion to use this type of evidence.

The occasions upon which participants' own written reports about an implementation experience have been published are, of course, likely lo be rure. Moreover, as with participant-observation, the potential bias of the participant must be questioned. Nevertheless, publications by participants do occur in major public policy situations (one need only think of the numerous first-person books about the Watergate coverup) and do represent another available source of evidence.

\subsection{USE OF MULTIPLE SOURCES OF EVIDENCE}

The previous subsections have noted the various ways in which evidence has been collected in the exemplary studies of implementation. Some of the strengths and weaknesses of these sources have been pointed out, and no single source appears to stand alone as the best for studying implementation or organizational processes. Indeed, one of the major lessons is that two or more of these sources should be used in any given study of implementation.

The use of multiple sources of evidence was a major feature of all 11 studies. The multiple sources were used mainly to achieve two different purposes, roughly analogous to the concerns with internal and external validity in experimental research design. First, multiple sources were used within a single case study to demonstrate a certain degree of consistency and corroboration about implementation events and interpretation (interna] validity). If information from an unstructured discussion is consistent with information from existing documents or field observations, for instance, the researcher's 
interpretation is more credible. This is not to say that implementation events necessarily have an objective truth; specific "facts of the matter" may differ, dedending upon the perspective of the particular actor. However, the multiple sources can and should be used to support the existence of these different perspectives, and even to explain them.

The use of multiple sources of evidence to achieve this first purpose of internal consistency and corroboration may sound somewhat like data collection methods in the field of history, where historians are taught to assemble different types of documents in writing their histories (e.g., Barzun and Graff 1977). However, a major difference with regard to implementation is that a contemporary event is usually the subject of study. This means that individuals who have participated in the implementation experience are available for interview, and direct observations about the events in question may also be made. These additional sources of information provide a rich and sometimes essential body of knowledge; but this information, with the partial exception of oral history projects, is not generally part of the historian's repertoire. To this extent, the multiple use of evidence in implementation studies is different from the multiple use as followed in the field of history.

The second purpose for using multiple sources of evidence was to extend the scope of study to cover more sites (external validity). As previously mentioned, multiple-site studies can be based on more intensive investigation of a few sites, combined with formal interviewing or other methods to cover (more superficially) a larger number of sites. The intensively investigated sites usually provide that basic information for interpreting and explaining the implementation process; the superficially investigated sites allow the investigator to expand the generalizability of the findings.

In summary, one of the methodological strengths of the exemplary studies of implementation appears to be their use of multiple sources of evidence: The plans for future studies should therefore explicitly call for multiple approaches and involve investigators who have a demonstrated ability to deal with more than one approach. Of the methods described, most future efforts should at least include the use of unstructured discussions, the examination of documents and news reports, and the use of field observations; whether structured interviews, participant-observation, or published reports by the participants can also be used will vary more so with the individual study. Whatever the combination, however, the collection of evidence was only one major step in the study of implementation. An equally important step is how evidence was analvzed, and to this topic we now turn. 


\section{SERI}




\section{SECTION 3.0}

\section{HOW EVIDENCE IS ANALYZED IN STUDIES OP IMPLEMENTATION}

By its loosest but still acceptable definition, "analysis" consists of a sifting, sorting, and combinatorial process. Various pieces of evidence are categorized, compared, and contrasted (e.g., Seltiz, Wrightsman, and Cook 1976, pp. 456-479). Where the evidence takes a quantitative form, analysis can be conducted through mathematical operations. In other situations, the analytic procedures are not so formalized, and researchers must follow a course of logical thinking that can only be validated by peer judgments or basic craft rules.*

By this definition, the analytic process was conducted in several ways by the exemplary implementation studies. This included a preanalysis step, a piecing together of the "facts" of the implementation experience, a merging of the evidence from various sources, an aggregating of single-site experiences (for the multiple-site studies), and most important, a testing of alternative explanations. Each of these procedures is described in the following subsections.

\subsection{PREANALYSIS}

Overfamiliarity with experimental research leads one to the simplistic belief that "data collection" and "data analysis" are completely isolatable steps. When one conducts an experiment, for instance, the pertinent variables are identified beforehand, data are collected, and analysis follows. However, in nonexperimental fields, whether a social science or a profession such as law or journalism, these two steps are not so clearly differentiated. In particular, analysis may occur as part of the process of collecting evidence. The analysis typically consists of on-the-spot judgments, whereby certain evidence is admitted into the body of a study, while other evidence is ignored.** This selection process is essential in studying an organizational process like implementation because the researcher's problem is that there is too much information that is potentially relevant. As Eugene Bardach (1977) has so aptly noted in comparing implementation (a complex process that occurs over a long period of time) with adoption (a specific decisfon-not necessarily unitary-that nevertheless occurs within a limited amount of time):

When one sets out to study the policy-adoption process, one has at least a starting point: the authoritative body, like a legislature, that has made [or will make] the ultimate decision on the issue. From there one can trace

*One of the remarkable features of Bernstein and Woodward's All the President's Men (1976), for instance, was the attention given to journalistic craft rules, wherein the reporters checked and corroborated various stories in the analytical process of piecing together the Watergate story. Often, participants were given a specific opportunity to deny or comment upon stories that where written about them.

**Examples would be decisions to interview newly discovered informants or to pursue a line of inquiry in dealing with documents or interviews. Even though there may have been a field protocol at the outset, modifications in data collection should not only be tolerated but may also be highly desirable. 
the various influences that led up to the decision. The nature of phenomenon thus restricts the scope of the relevant data ... the nature of the implementation process is exactly the opposite: instead of becoming concentrated in one place, it gets dispersed at every place (Bardach 1977, pp. 310-311, emphasis mine).

The selection process, as well as other implicit analytic steps that occur during the data collection phase, is part of what may be called "preanalysis." Among the exemplary studies, the extent of preanalysis varied widely. In several studies (\#1, 4, 5, 8, and 10) the researchers clearly had access to a vast amount of initial information, only some of which became a formal part of the subsequent study. For most of the single-site studies (or the single-site components of the multiple-site studies), the preanalysis methodology was rarely described or even addressed as an issue. In one exception (\#11, p. 16), the preanalysis step consisted of the development of an explicit chain of evidence, in which links between data collection protocols, narrative case studies, and "key events" were deliberately fashioned; the key events then became the data base for the aggregate analysis. In other studies (e.g., \#2 and 6) certain quantitative evidence was used and was therefore specified more clearly through the use of an interview instrument or other observational protocols.

Even though the selection process was not well described in most of the exemplary studies, its nature can well be imagined. Whether researchers are working with unstructured discussions or available documents, some type of notes or records must be created. Ultimately it may be presumed that the notes or records will serve as part of the researcher's information base, and hence constitute the "evidence" to be considered as part of the study. The first phase of the selection process has already taken place, however, because the researcher has had to decide on the information to be entered into the notes or records. Clearly, not every piece of information will have been entered, and the implicit rules by which certain information is ignored becomes the essence of the selection process.

Other preanalysis activities may include decisions regarding: (1) the way that key concepts can be made operational-e.g., data found in the field may suggest a different set of measures than originally planned, (2) the depth and detail for pursuing a line of inquiry, and (3) the evolution of "categories" or classification schemes whereby notes are initially recorded. In experimental research, most of these activities are part of a study's "research design," and are normally specified ahead of time. In the exemplary studies of implementation, as with other studies of organizational processes more generally, a formal research design cannot usually be so specific and hence the preanalysis activities go largely undescribed. Even so, a more rigid research design would prevent an investigator from fully exploiting field opportunities.

\subsection{PIECING TOGETHER THE "PACTS" OF THE IM PLEMENTATION EXPERIENCE}

In dealing with single-site studies (or the single-site reports of multiple-site studies), the most common form of analysis is the piecing together of the major events in the implementation experience. These events have to do with organizational changes, critical meetings, personnel tumover, or other activities that form part of the implementation experience. The piecing together process is considered an analytic sted because some type of classification scheme, or set of categories, must be used. 
The reporting of these events was done in several ways by the exemplary studies. A few of the studies (\#1, 3, and 4) contained a formal chronology of events, of which a sample is illustrated in Table 3-1. The sample shows both the types of activities and the fact that a temporal sequence is the organizing theme. Other studies (e.g., the individual case studies found in \#5, 7, and 9) did not construct a formal chronology, but the narrative description of the individual site reports was organized according to a chronological sequence. Finally, a third approach was to organize major portions of the text of the entire study according to a general sequence of phases or stages of events over time (e.g., \#2, 10, and 11).

The use of temporal sequence to piece together the facts of the implementation experience should not be taken for granted. The temporal sequence is a significant analytic step because it allows the researchers to establish the basis for some causal inferences. In general, as with historical analysis, a set of earlier events can be considered as candidates for having caused the occurence of a set of later events (at a minimum, such a sequencing eliminates the possibility of using later events as causal explanations of earlier events). However, it should not be assumed that the temporal sequencing is the only way of organizing a text; the experimental paradigm, for instance, does not follow such a sequence, and there have been many narratives of organizational processes (though none among the exemplary studies) that may be organized topically rather than te mporally.

In addition to the temporal sequencing, implementation events were pieced together in other ways. In one of the exemplary studies (\#1), for instance, the investigators were strongly interested in the apparent complexity of the implementation process. They defined the notion of complexity as a function of the number of decision-points and participants that were involved in their single-site study. Thus, a key part of the analysis consisted of a tabulation of the decision-points that occurred during implementation, with the findings that there were 30 such points, involving the necessity for some 70 different agreements among numerous participants (\# 1, pp. 103-106). The investigators then went on to make inferences about the effects of the number of decision-points on implementation delays and the probability of implementation success.

\subsection{MERGING EVIDENCE FROM VARIOUS SOURCES}

Another analytic step common to all of the exemplary studies was the merging of evidence from various data sources. All of the studies, as previously noted, had employed multiple sources of evidence. This approach to data collection thus necessitated, at the analytic stage, some type of commingling process.

The commingling process was done by both informal and formal means. An informal approach has already been described earlier, where it was noted that documentary information could be combined with evidence from unstructured discussions, to assemble the implementation experience (see Section 2.3). This was a common step for combining these two types of evidence, and characterized most of the descriptions of individual site experiences. This approach was usually conducted in such an informal manner, however, that the reader could not always tell when such merging had occurred. It is assumed, for instance, that narrative descriptions containing no formal footnotes or citations (e.g., \#4, 5 , and 8) but in which introductory passages indicated the use of several sources of evidence, reflect the merging of evidence from these various sources. 
Table 3-1. ILUSTRATIVE CHRONOLOGY FROM 1 YEAR OF NELKIN (1973) STUDY

1970

March

Boudreau discusses possibilities of methadone maintenance program with St. Joseph's Hospital and Dr. Pittenger.

Apr il

Boudreau submits application for accreditation of the methadone program to the NACC for $\$ 162,000$ for fiscal year ending March 31,1971 . Announces plans to seek local and state approval.

June

Negotiations between the county Department of Mental Health and St. Joseph's Hospital.

August 25

Health Committee of Onondaga County Legislature approves proposal and provides a $\$ 25,000$ loan to initiate a program.

September 10

NACC approves county application and funder $\$ 99,523$ from September 1, 1970 to March 31, 1971. Accreditation given through August 31, 1972.

September 10

County legislature unanimously approves program.

September 15

Request for FDA forms and approval procedures. Request for approval procedures from Internal Revenue Service. St. Joseph's Hospital is informed of application procedures and FDA forms are sent to the hospital.

September 22

Application for certification and registration is sent to New York State Bureau of Narentics Control.

September

Negotiations concerning required laboratory support.

October 1

Ocluber 10

Intended opening date.

State Department of Health application is sent to St. Joseph's Hospital.

December 24

County Department of Mental Health fills out FDA form when it is rcalized that hospital had nnt yet done so. 
More formal approaches to the commingling process typically occurred where studies had collected more than one type of quantitative evidence. For instance, tabulations of field observations could be compared with tabulations from interview data (e.g., \#2), with the inferences from each type of tabulation compared to arrive at a consistent picture of the implementation experience. In this particular exemplary study, this procedure was also followed by merging information from unstructured discussions with that from formal interviews, giving the reader confidence that each finding was based on the entire repertoire of potentially relevant evidence. Similarly, a second study examined separate tabulations, covering identical issues, but where one set of evidence came from an intensively studied set of sites and the other set of evidence came from telephone interviews (\#11, pp. 139-156). However, in both these as well as other instances, the exemplary st udies did not actually merge the evidence through the use of any formal, mathematical operation; what merging occurred really consisted of analytic comparisons of the findings from the various sources of evidence.

In a few cases, mathematical operations were used to create complex measures, based on several variables, but from the same source of evidence. Thus, one study defined its basic measure of implementation from a combination of questions from formal interviews-representing " ... a coding from a variety of questions" (\#6, Vol. VII, pp. 151152).

\subsection{AGGREGATING EXPERIENCES FROM MORE THAN A STINGLE SITE}

This analytic step was only characteristic of the multiple-site studies, where there was a need to derive general findings and conclusions on the basis of observations made at several implementation sites. The exemplary studies coped differently with the aggregation problem. Most commonly, each multiple-site study contained a narrative portion that aggregated the lessons from individual sites by "naming" each site wherever it was relevant. Thus, a typical text from one multiple-site study, in which all the component sites are named, is the following:

Four years after the start of the surplus land program, only 120 units of housing had been built. At Fort Lincoln, where this housing stood, no other construction was under way. In Clinton Township [outside of Detroit], 160 units were being built. In Atlanta, a developer was ready to start, but was being delayed by a citizens' suit. In Louisville, approval had only recently been received from the board of aldermen. In San Antonio, New Bedford, and San Francisco, the projects had been cancelled. This chapter analyzes why the program produced so little (\#5, p. 83).

A slightly more formal version of this narrative approach was to present simple tabulations of the relevant characteristic at each site, so that the reader could independently discern the validity of the aggregate observation. One study's main conclusion had to do with the importance of a "bureaucracy-centered entrepreneur" in the implementation process (\#10, Analysis and Conclusions Volume, pp. 169-182). The support for this conclusion was provided by identifying and tabulating the presence or absence of such an entrepreneur for each of the component sites, and by showing that such an entrepreneur did exist in a majority of the cases. A similar approach was used in another study, which conceptualized the implementation and institutionalization process as a function of 10 organizational "passages and cycles" (\#11). The occurrence of each passage and cycle, as well as their sequence, was formally tabulated throughout the study as the basic measure of the degree to which implementation or institutionalization occurred. Tabulations, in 
the form of matrix presentations, were also used in a third study (\#9) that searched for characteristics of successful demonstration projects (see Table 3-2).*

Other studies coped with the aggregation process in somewhat less convincing fashion. One multiple study (\#8) did not enumerate the individual sites at any point in the text, merely discussing the "modal" site throughout the analysis. This approach may be justifiable with such a program as methadone maintenance clinics, where the implementation of clinic operations may have followed a similar course of events at different sites. However, an explicit enumeration of the individual sites would normally have been more preferable. In two other studies (\#6 and 7) there also was little articulated connection-either through narrative "naming" or through formal tabulations-between aggregate statements and the experiences at individual sites.**

\subsection{TESTING ALTERNATIVE EXPLANATIONS}

Overall, no single analytic step was as important as the testing of alternative explanations. In fact, this step may, in itself, capture the essence of studying implementation and other organizational processes. Viewed another way, this step represents the culmination of the other analytic steps; after a preanalysis, a piecing together of the facts, the merging of various types of evidence, and the aggregation of single-site experiences, the investigator is left with the task of explaining why implementation occurred as it did.

\subsubsection{Explanation Construction and Testing}

The construction of an adequate explanation is a complex and difficult affair. There exist no formal definitions of an "explanation," and no descriptions of the methodologies whereby explanations should be constructed or tested. The key to an explanation is that it should identify a causal sequence that covers the relevant facts of the implementation experience. Notions of "elegance" and "parsimony," as used in logic and philosophy, are also relevant. Yet, one must note that the researcher himself/herself must determine the scope of the "relevant facts," as well as the reasonable levels of parsimony or elegance.

An analogous example derives from the craft of detective work, whereby a detective must construct an explanation for a crime. Presented with the scene of the crime, its description, and possible reports from eyewitnesses, the detective must constantly make decisions regarding the relevance of various factors. Some facts of the case are clearly likely to be misleading or unrelated to the crime; other clues must be recognized as such

*The careful reader will note that the sites in the matrices represent three different cohorts or samples, with the first set of eight sites having served a "hypothesis generation" and "instrument development" function. To the extent that this was true, it is incorrect to tabulate these sites with the other two samples, as this represents a classic case of mixing the "calibrating" cases with the "test" cases.

**In study \#6, there are numerous tabulations of formal interview data (e.g., see Volumes II and VII). However, aggregate conclusions from field observations, with explicit references to Individual sites, were presented in one volume (III) but not another (VI). 
Table 3-2. ILLUSTRATIVE TABULATION OF MULTIPLE SITES

PROM BAER ET AL. (1976)

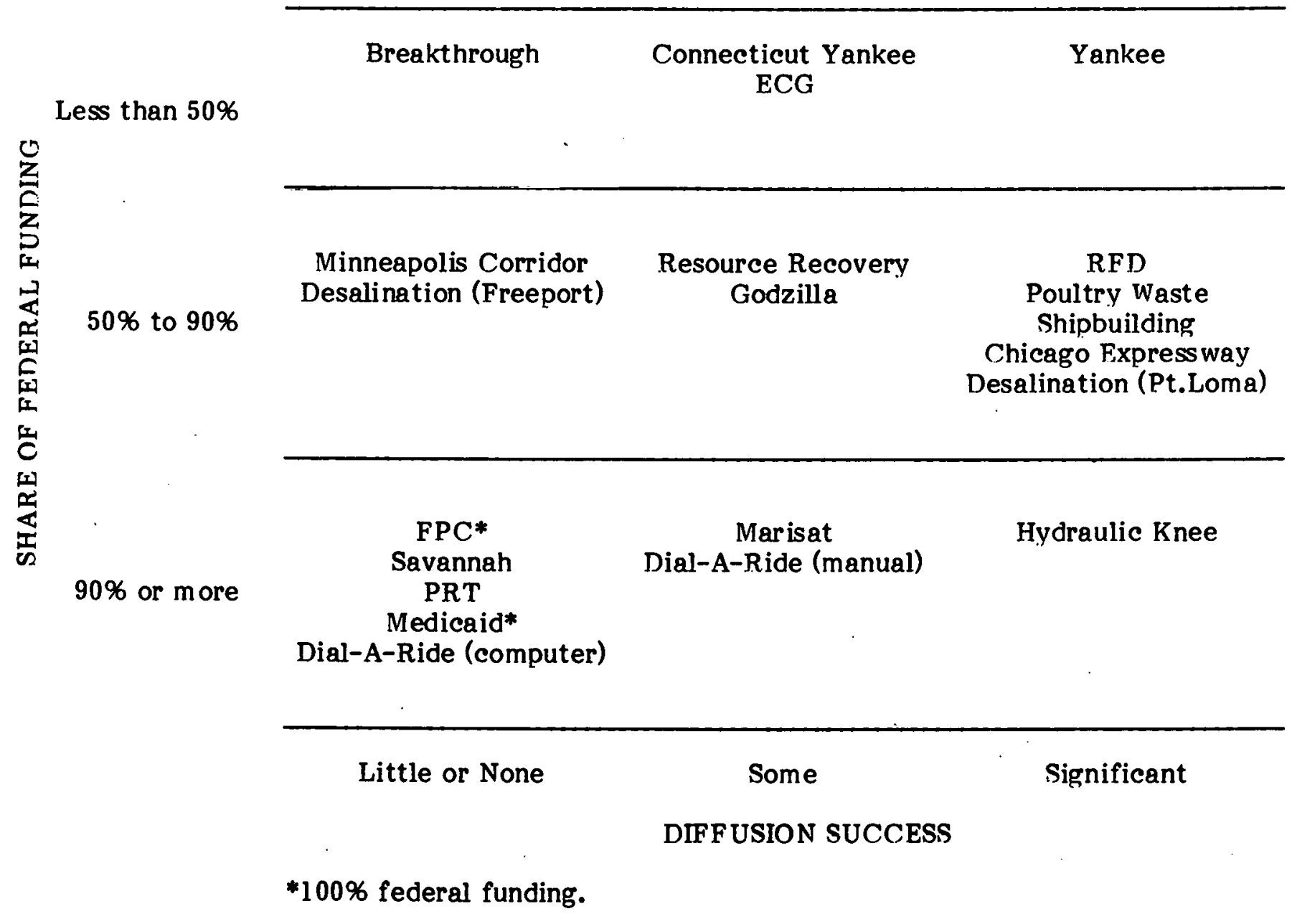


and pursued vigorously. The adequate explanation for the crime then becomes a plausible rendition of a motive, opportunity, and modus operandi. If the detective is then confronted with another case, where the relevant factors appear to be similar to those of the first case, he or she may try to test the first explanation and establish that both crimes were committed by the same perpetrator. Note that modification may be necessary in the second explanation-and the detective must learn how to ignore irrelevant variations from case to case even though the same modus operandi is involved. How the detective carries out this work (1) in initially determining what is relevant, (2) in then constructing an adequate explanation of what has occurred, and (3) in knowing the acceptable levels of modification in the original explanation as new cases are encountered, may be considered a task that is analogous to what confronts the researcher who studies implementation.*

One of the few descriptions of this research task may be found in one of Donald Campbell's lesser-known articles (1975). In this article, Campbell defends the rationale for conducting one-shot case studies, a research design he had previously discredited (Campbell and Stanley 1966). According to Campbell, the search for an explanation is a kind of pattern-matching process. The process can be applied even if there is only a single case, because the pattern requires a fit based on the multiple implications derived from an explanation or theory about the case. Thus, it is incorrect to judge this situation by the norms of experimental design, which would stipulate that a single-case study (or even a small group of cases) could never provide a compelling rationale for establishing the importance of a single factor (or determinant).** An explanation, and not a single factor, is what is being tested, and this accounts for the frequent outcome where:

Even in a single qualitative case study the conscientious social scientist often finds no explanation that seems satisfactory. Such an outcome would be impossible if [single factors were being tested -there would instead be a surfeit of subjectively compelling explanations (Campbell 1975, p. 182).

More research needs to be done in defining explanations and the pattern-mutching process. However, even this preliminary description by Campbell does sound much like the analogy from detective work and like the analytic approaches followed in the exemplary studies.

The exemplary studies dealt with the explanation problem in three different ways. First, two studies (\#3 and 4) provided no explanation of the implementation experience, nor did they purport to do so. The studies only contain a description of the experience, but the description is so rich and insightful that the reader is tempted to develop his or her own explanation of why implementation succeeded. [In one study (\#4), explanations are offered, but on topies other than implementation]

*For some background readings for this analogy, see Sanders (1976).

**Technically, Campbell claims that the interpretation from the viewpoint of experimental design is based on the incorrect notion that there is only a single degree of freedom (or few, where only a few case studies are involved); in reality, Campbell claims that the population of multiple implications from a single explanation or theory produces multiple degrees of freedom. 
Second, most of the studies did attempt to construct explanations of the implementation process, whether based on single- or multiple-site experiences. Two studies made it quite clear, early in the text, that the overarching objective of the study was to arrive at a satisfactory explanation and the reader is constantly faced with this challenge. In the first study, the goal was to explain implementation failure in spite of a low initial resistance to change (\#2, pp. 7-10);* in the second study, the explanation had to cover an initially sensible idea for a federal program that nevertheless failed in its implementation at seven sites $(\# 5$, p. 21). This second study provides an excellent example of how a researcher develops an initial explanation and "carries" the full explanation from site to site, modifying the explanation along the way (\#5, pp. 90-95). Three other studies (\#6, 10, and 11) demonstrated their arrival at an explanation through a prescriptive mode; the texts of these studies conclude with strategies and policy recommendations that therefore imply knowledge of causal process.

Third, two ot her studies (one a single-site study and the other a multiple-site study) not only constructed an explanation and tested it against the study's own evidence, but also compared explanations with those from ot her studies (\# 1, pp. 90-91, 142; and \# 8, pp. 325326). One study (\#1) concludes its comparative discussion by noting that:

In both the new towns [a study conducted by a previous investigator] and the Oakland EDA programs [the subject of the present study], we find similar phenomena: federal grandeur, inadequate local support, and a divorce of implementation from policy (p. 142).

Ironically, the other study (\#8) concludes by modifying the explanations offered by the first study (\#1), suggesting that the nature of federal-local interactions will differ, depending up on whether federal policies have relatively little control over a local phenomenon (as in economic and community development) or in fact assert a monopolistic control (as in supporting the operation of methadone maintenance clinics).

\subsubsection{Determinants Approach}

At least two studies (\#7 and 9) followed a slightly deviant approach to this analytic step. Instead of attempting to construct an explanation of the implementation experience, these studies tried to ldentify the key determinants associated with implementation success or failure.** The determinants approach is different from the explanatory

*The design of this study may actually represent a classic use of the one-shot case study. The authors identified "resistance to change" as an explanation that was highly prevalent in the literature at that time. They then chose to test this explanation by deliberately selecting a site predisposed to change (and their initial measures corroborated this predisposition), but which nevertheless encountered implementation problems. This may represent a social science variation of the critical experiment in biology or beharioral research (see Boring 1950, pp. 356-360), in which a critical set of variables is tested within a single experiment. The results should enable the experimenter to draw a conclusive decision between competing theories underlying the choice of variables; the more significant the theories, the more critical the experiment.

**For a brief review of previous organizational studies following the determinants approach, see Yin (1979, pp. 373-375). 
approach in that the identification of key determinants does not in itself provide a causal description of how an organizational process occurs (Mohr 1978). For instance, a determinant might be the observation that:

...the greater the participation of different interest groups in the overall project, the more likely the success of the implementation (\#7, p. 4).

Such an observation, even if combined with the identification of other key determinants, does not provide an explanation of how and why implementation occurs. One study that followed the determinants approach (\#9) later did try to construct an explanation in terms of policy recommendations regarding the design of future demonstration projects (compare Parts I and II of the summary report). However, the basic evidence of the study was cast in terms of identifying determinants rather than in analyzing processes, and thus it is difficult to have confidence in these later policy recomendations.*

By its very design, the determinants approach falls short of providing a full explanation. Again, to refer to the analogous situation of detective work, one curn imagine the dissatisfaction if a detective were to conclude with the observation that the determinants of a series of crimes were a particular type of household, a certain time of day, and a common weapon. The observation of these determinants would in actuality be the beginning, and not the concluding step in constructing an explanation of how, why, and by whom the crimes had been committed. In short, the determinants must lead to a fuller theoretical statement that yields the necessary understanding or explanation of the causal process (e.g., Yin 1977b).

Interestingly, the worst offenders of the determinants approach have not been the exemplary studies where, as we have seen, only one or two studies erred in this direction. Unfortunately, the worst offenders tend to be those who have attempted to synthesize, through secondary review, the results of numerous empirical studies (e.g., Zaltman et al. 1973; Rothman 1974; Public Affairs Counseling 1976; Fullan and Pomfret 1977). Each of these reviews typically arranges its text by sequentially reviewing the findings on key factors or determinants of organizational change (e.g., factors involving the nature of the innovation, the nature of the innovating agency, the external environment, etc.). According to one analyst (Mohr 1978), these attempts to identify individual determinants are part of a "variance theory" approach, in which the main research result is to account for statistical variation in some dependent variable. The approach is thus not surprisingly bereft of helpful insights, because a "process theory" approach-describing the causal steps in some detail-is what is really needed. The variance theory approach, in short, does not provide insights into the way that the innovation or implementation process might work.

In contrast, studies and reviews could set out to compare alternative and competing explanations. Once example of such an approach is Richard Elmore's discussion of four models of program implementation-systems management, bureaucratic process,

* What may have happened in this latter study was that the investigators, in the course of conducting their study, developed legitimate knowledge about implementation processes; but this knowledge was not formally presented as part of the study's evidence, thus leaving the reader ignorant about the information base used to support the policy recommendations. 
organizational development, and conflict bargaining (F.lmore 1978). Each model, based on an existing body of empirical research, is a full narrative description of an alternative explanation of why implementation occurs or fails to occur. The descriptions cover the basic assumptions of each model in terms of how organizations work, the philosophical and value-laden differences among the models, and finally, the alternative (and in some cases, competing) predictions derivable from each model.

\subsubsection{Summary}

To summarize this portion of the discussion, the most important analytic challenge is to construct and test an explanation of the implementation experience. Where evidence only comes from a single site, the explanation can nevertheless be "tested" by: (1) attending to the pattern of results, and (2) determining the degree to which the pattern matches that predicted by the explanation. Where evidence has been collected from two or more sites, the same procedure may be augmented by applying the full explanation to each site individually, with the explanation being modified as each site is considered. In contrast, the enumeration of a set of determinants is an insufficient substitute for this explanation-testing process. 


\section{SE키}




\section{SECTION 4.0}

\section{REASONS POR BELIEVING THE CONCLUSIONS OF IMPLEMENTATION STUDIES}

The preceding sections have traced the ways in which exemplary studies of implem entation have been conducted, focusing on the collection and analysis of evidence. Many specific examples have been cited to guide future researchers in conducting their own studies of implementation or of organizational processes more generally. But another theme has also emerged that the alert reader should have caught and that requires explicit attention: the research craft or methods associated with these implementation studies appear not to be rigidly defined or even very rigorous by standard laboratory or research criteria. Thus, for instance, a preanalysis step seems critical to the amassing of evidence but is rarely described; "unstructured discussions" are a common source of evidence; multiple sources of evidence are commonly used, but the way in which the varied evidence is later merged is not a formalized procedure; and the culminating stepexplanation-building and testing-appears to follow few methodological guidelines.

In the light of this state of affairs, why should a reader believe the results of these exemplary studies? Moreover, why are they exemplary studies? Could the rest of the lot be that much worse? These and related questions cannot go unanswered if the goal is to advance craft knowledge, and the purpose of the present section is to suggest that good answers may actually be available.

\subsection{FORMAL METHODOLOGICAL DISCUSSIONS}

One obvious answer-that each study contained a detailed methodological statement that justified its choices or indicated an awareness of potential biases and shortcomingsturns out to be an incorrect one. Of the 11 exemplary studies, only four (\#2,6,9, and 11) had what could be regarded as comprehensive methodological discussions, covering site selection, data collection procedures, and copies of key protocols or instruments. Moreover, one of these four studies makes a strong reservation in warning the reader about its m et hods:

... the rcscarch aim was not to test lyputheses but to enable the formulation of hypotheses... O Our operational measurements of both independent and dependent variables can be challenged,... the selectivity of our sample raises questions about the generalizability of the findings; and the statistical procedures and the interpretation of the results are open to valid criticism and alternative . interpretations. These caveats notwithstanding. . . (\#6, Volume VII, p. viii).

A fifth study (\#10) contained a very brief methodological discussion, mainly covering the issues of site selection. However, the remainder of the 11 studies had virtually no discussion of their methodologies; what few words were said usually appeared in a brief footnote or in the acknowledgments portion of the report.

The absence of formal methodological discussions may, in retrospect, have been a collectively wise choice. Such discussions would probably have revealed a whole host of shortcomings, by any criteria derived from expcrimental research, and would also have been difflcult to describe because of the varied methods that we have seen were used. For many of these studies, the development of a methodological discussion might even have led, paradoxically, to a decreased sense of confidence in the study and its results. 
Clearly the authors, many of whom hold esteemed academic or applied research positions, relied on some other factors to give the reader confidence in the results and conclusions. These factors may be said to fall into two categories-internal and external credibility-concepts that seem useful for judging this type of research in the future.

\subsection{INTERNAL CREDIBHITY}

Internal credibility stems from the information and evidence presented in the body of a study itself. Such credibility was bolstered in several ways by the exemplary studies, the most important of which was the correctness of the basic facts of the implementation experience. Although such facts are always disputable, many of the key implementation events, as noted earlier, tended to be publicly knowable events in that newspaper accounts or other official records could be checked to confirm the researcher's narrative. At the same time, the strength of the researcher's case did not necessurily lest on the absolute correctness of every single fact. The main strength usually lay in the overall pattern of events, where the misconstruing of one or two events would not be enough to call the entire rendition into question. Moreover, the difficulty of constructing this overall pattern should not be overlooked. The authors of the various exemplary studies all appeared to have spent considerable effort in covering different sources of evidence and producing a thorough description of the implementation experiences at individual sites. Thus, a first requirement for internal credibility, met by most of the exemplary studies, was the provision of a clear factual account of the implementation experience.

Added to the integrity of the basic facts of the implementation experience was another feature that increased the credibility of a study. This was the researcher's recognition of different points of view by the various participants in the implementation experience.* Such recognition constitutes an acknowledgment that most organizational changes, by dint of different role perspectives, are likely to involve conflicting viewpoints. Organizational change, simply put, is not usually a congenial process. Most of the exemplary studies were able to construct explanaliors thut not only accounted for the varinus events but also appreciated the different viewpoints.

One of the more extreme examples of this phenomenon of appreciating different viewpoints also suggests a high degree of sensitivity on the part of the investigators. In this example, the issue under discussion was that of the value differences between practitioners and analysts in a study of manpower changes in local agencies. The analytic approach had been primarily based on the concept and measurement of travel time, or the amount of time required for a fire vehlcle to liavel to the scenc of a fire alarm. The analysis had shown how agencies could make manpower reductions without affecting travel time (or could decrease travel time by rearranging existing resources). However, the analytic results were continually called into question by the firefighters at one of the implementation sites. The firefighters did not appear to disagree with any of the finer points of the analysis. As described in one newspaper account that was quoted by the study:

The dispute hinges on the firefighters' refusal ... to accept, for purpose of decision-making, the validity of travel time as a performance measure ... The firemen argue that it's the men who put out the fires, not the response time (\#7, pp. 64 and 73, emphasis mine).

*This appreciation of different viewpoints has been a main feature in using case studies for teaching purposes. See Stein (1952, pp. $x x-x x x)$. 
In a way, the firefighters had a legitimate point of view. As so frequently happens in situations of this sort, disagreements arise over the fundamental assumptions made by one participant or another, and not over a particular approach or methodology. Yet, this state of affairs has only seldom been recognized.

Finally, internal credibility was bolstered by the knowledge that the participants in the implementation experience could and did have an opportunity to voice their opinions about the researcher's findings. In one study (\#5), a key participant actually wrote the foreword to the study, implying an endorsement of sorts over the integrity of the effort. In another study (\#11) the individual site descriptions were given for review, in draft form, to the persons that had been interviewed as part of the study. In the other studies, because the implementation events were relatively recent and highly visible, participants could have been asked to comment, if needed, to corroborate the findings.*

\subsection{EXTERNAL CREDIBUITY}

External credibility, in contrast to internal credibility, is based on inferences about a study, how it was conducted, and the researcher's previous work. For the exemplary studies, credibility in the results and conclusions was especially enhanced by two external criteria: the researcher's reputation for scholarly endeavors, and the broad level of effort that was involved in conducting the study.

Judgments about a researcher's reputation are difficult to make. However, in all but one of the exemplary studies, the researchers had developed multi-year associations with the research topic being studied and with the research community at large.** In all but one case (\#3), for instance, the researchers had previously published books or articles on organizational topics similar to those of the exemplary studies, either in the form of prior case studies of agency experiences or in the form of publications on related technologies. This type of extended career interest gives the reader additional confidence that the researcher issues in the exemplary study have been carefully considered over a broader period of time. Although there are occasional injustices in using this type of criterion to make judgements about researchers (e.g., see Merton 1968), the main point is that these investigators were no "instant experts." Furthermore, most of them did their research within a broader organizational context-whether academically based or notthat reinforced a career interest in the implementation topic.

The second external criterion had to do with the time and effort put into these exemplary studies and their general breadth and depth of coverage. One substantive lesson about implementation is that it is a complex process that can take several years to complete. Thus, as noted by one of the exemplary studies:

*In only one of the exemplary studies (\#2) was the implementation experience actually reported in anonymous fashion, with neither the location of the site nor the names of the relevant agencies or participants given. However, even under these conditions, portions of the text may be shown to participants for their corroboration and correction.

**Note that this observation does not automatically follow from the operational definition of "exemplary" study that was used to select these 11 studies; if the observation had followed from the prior definition, the argument presented here would be circular. 
The picture that results, ... even for an innovation so straightforward as manpower rescheduling, is one of great complexity. A large number of people, many decisions, and a long period of time were required before a new manpower scheduling system became an operating reality (\#3, p. 301).

In this particular case, the implementation process took 4 years from the initial conception of the idea within city government to full operation within one of its agencies. In other cases, equally long periods of time were involved; for instance, for federally supported implementation projects in education, the typical award period was 3 to 5 years (\#6). For innovations in broader fields such as community or economic development, the implementation process can be even longer and involve even more participants and more decision points.

If the implementation process is assumed to be such an extensive affair, it is safe to conclude that investigators will be more expert in their judgements if they spend mule time and effort in conducting their studies. The exemplary studies, especially when judged against the typically brief time period allowed by sponsored research, were genuinely exemplary in this regard. First, all but one of the multiple-site studies were largescale team efforts, in which several senior investigators contributed to the final effort. Second, in several of the studies the investigators actually spent lengthy periods of time "on-line" with the implem entation experience, ranging from a full academic year of field observations (\#2) to 3 calendar years of participant-observation (\#3). Third, most of the studies, where funded by an external agency, involved multi-year awards. One study, for instance, noted that the implementation report represented "... the culmination of 5 years of support for the documentation, testing, and evaluation of methods ...." (\#7, p. v). Another study (\#6), as judged by a third party (Fullan and Pomfret 1977), was the most comprehensive study of implementation in the field of education and was also conducted over a 5-year period. Fourth, the published version uf several of the studice was sometimes only the tip of the iceberg, with numerous student papers and lesser efforts also known to have been part of the overall project (e.g., \#1). All these factors serve to raise confidence that the implementation experiences were well analyzed.

To return, then, to the initial set of questions regarding the credibility of these studies, the basic conclusion is that various factors other than formal methodological discussions give the reader adequate reason to have trust in the results and conclusions from these studies.

\subsection{CONCLUDNG COMMENTS}

This conclusion appears consistent with the notion that craft knowledge in the study of implementation and related organizational processes may be just in its infancy. A mature field, by contrast, is more likely to have formalized methodological procedures.

The findings also suggest several ways in which implementation research may be improved in the future. First, the collection of evidence on implementation was found to consist of the use of multiple suurces of information. Most of these data collection methods have been documented in typical methodological textbooks, but the unique flavor in the implementation studies is that the investigator must be facile with the entire variety. Methodological generalists rather than specialists may therefore be increasingly needed if implementation research is to thrive. How one trains such generalists, identifies them in research proposals, or judges their qualifications, are issues that should be of concern to universities and research-funding agencies. 
Second, the analysis of evidence was found to consist of a number of activities-e.g., explanation-building, preanalysis, piecing together of the fact, etc.-for which there has been little methodological research or documentation. Unlike the situation with data collection methods, existing textbooks rarely address these analytic activities. One suggestion for improving future research is that investigators who currently conduct implementation studies ought to be asked to introspect about their analytic craft. The introspections should become part of the public record, and a body of methodological knowledge may emerge. Such efforts of course could be enhanced by the initiation of formal methodological research projects.

Third, the absence of formal methodological statements in implementation and related studies should not be considered, at this time, a serious deficiency. The craft is simply not well established, and a formal methodology might become a counterproductive straightjacket. However, the ability to make formal methodological statements should be an increasing goal in the future. Without the development of formal methodologies, research on implementation will probably continue to be limited to seasoned investigators; because there is only a limited number of such investigators, substantive breakthroughs on implementation are likely to be intermittent and sparse. In contrast, the development of formal methodologies should be seen as a way of allowing a larger pool of investigators to participate in implementation research-at the same time retaining a high level of research rigor. The formalization of craft knowledge, in brief, permits more investigators to participate in a research field, thereby creating increased competition, more opportunities for corroboratory findings, a greater abundance of ideas, and other conditions through which substantive knowledge can only benefit. The present paper has hopefully made a small step toward formalization simply by enumerating and analyzing the methods used in exemplary studies of implementation. 
SERI 


\section{SECTION 5.0}

\section{REFERENCES}

1. Allison, Graham 1971. Essence of Decision: Explaining the Cuban Missile Crisis (Boston: Little, Brown).

2. Attewell, Paul and Dean R. Gerstein 1979. "Government Policy and Local Practice," Am erican Sociological Review, 44:311-27, April.

3. Baer, Walter S., et al. 1976. Analysis of Federally Funded Demonstration Projects (Santa Monica, California: The Rand Corporation).

4. Baer, Walter S., et al. 1977. "Government-Sponsored Demonstrations of New Technologies," Science, 196:950-957, May.

5. Banfield, Edward C. 1973. "Making a New Federal Program: Model Cities, 196468," in Allen P. Sindler (ed.), Policy and Politics in America (Boston: Little, Brown), pp. 125-158.

6. Bardach, Eugene 1977. The Implementation Game: What Happens After a Bill Becomes Law (Cambridge, Massachusetts: MIT Press).

7. Barnes, Louis B. 1971. "Organizational Change and Field Experiment Methods," in James D. Thompson and Victor H. Vroom (eds.), Organizational Design and Research (Pittsburgh: University of Pittsburgh Press), pp. 57-111.

8. Barzun, Jacques, and Henry F. Graff 1977. The Modern Researcher, 3rd ed. (New York: Harcourt, Brace and World).

9. Berman, Paul 1978. "The Study of Macro- and Micro-Implementation," Public Policy, 26(2): 157-184, Spring.

10. Berman, Paul, and Milbrey McLaughlin 1976. "Implementation of Educational Innovation," The Educational Forum, 40:347-370, March.

11. Berman, Paul, and Milbrey McLaughlin 1974-1978. Federal Programs Supporting Educational Change (Santa Monica, California: The Rand Corporation, Vols. 1-8).

12. Bernstein, Carl, and Bob Woodward 1976. All the President's Men (New York: Warner Books).

13. Bernstein, Ilene, and Howard Freeman 1975. Academic and Entrepreneurial Research (New York: Russell Sage).

14. Bingham, Richard 1976. The Adoption of Innovation by Local Government (Lexington, Massachusetts: Lexington Books).

15. Boring, Edwin G. 1950. A History of Experimental Psychology, 2nd ed. (New York: Appleton-Century-Crof ts).

16. Campbell, Donald T. 1975. "Degrees of Freedom and the Case Study," Comparative Political Studies, 8:178-193, July.

17. Campbell, Donald T., and Julian C. Stanley 1966. Experimental and QuasiExperimental Designs for Research (Chicago: Rand McNally).

18. Corwin, Ronald G. 1975. "Innovation in Organizations: The Case of Schools," Sociology of Education, 48:1-37, Winter.

19. Daft, Richard L., and Selwyn W. Becker 1978. The Innovative Organization: Innovation Adoption in School Organizations (New York: Elsevier). 
20. Derthick, Martha 1972. New Towns In-Town: Why a Federal Program Failed (Washington, D.C.: The Urban Institute).

21. Douds, Charles F., and Albert H. Rubenstein 1975. "Review and Assessment of the Methodology Used to Study the Behavioral Aspects of the Innovation Process," in Patrick Kelly et al. (eds.), Technological Innovation (Atlanta: Georgia Institute of Technology, F ebruary), pp. 185-269.

22. Downs, George W., Jr. 1976. Bureaucracy, Innovation, and Public Policy (Lexington, Massachusetts: D.C. Heath).

23. Downs, George W., Jr., and Lawrence B. Mohr 1976. "Conceptual Issues in the Study of Innovation," Administration Science Quarterly, 21: 700-714, December.

24. Eckstein, Harry 1975. "Case Study and Theory in Political Science," in Fred I. Greenstein and Nelson W. Polsby (eds.), Strategies of Inquiry (Reading, Miassachuset ts: Addison Werlcy), pp. 79-137.

25. Elmore, Richard F. 1975. "Lessons from Follow Through," Policy Analysis, 1:459484, Sum mer.

26. Elmore, Richard F. 1978. "Organizational Models of Social Program Implem entation," Public Policy, 26:185-228, Spring.

27. Eveland, J. D., et al. 1977. The Innovation Process in Public Organizations (Ann Arbor: Department of Journalism, University of Michigan, March).

28. Feller, Irwin, et al. 1974. Diffusion of Technology in State Mission-Oriented Agencies (University Park: Institute for Research on Human Resources, Pennsylvania State University, October).

29. Feller, Irwin, et al. 1976. Diffusion of Innovations in Municipal Governments (University Park: Institute for Researçh on Human Resources, Pennsylvania State University, June).

30. Fullan, Michael, and Alan Pomfret 1977. "Research on Curriculum and Instruction Implem entation," Review of Educational Reserreli, 47:335-397, Winter.

31. Greenberg, George D., et al. 1977. "Developing Public Policy Theory: Perspectives from Empirical Research," American Political Science Review, 71:1532-1543, December.

32. Gross, Neal, et al. 1971. Implementing Organizational Innovations (New York: Basic Books).

33. Hargrove, Erwin C. 1975. The Missing Link: The Study of Implementation of Social Policy (Washington, D.C.: The Urban Institute).

34. Iannacone, Lawrence, 1975. "The Field Study in Educational Policy Research," Education and Urban Society, 7:2220-238, May.

35. Lambright, W. Henry, 1977. Adoption and Utilization of Urban Technology (Syracuse: Syracuse Research Corporation, September).

36. Lambright, W. Henry, and Paul Flynn 1977. "Bureaucratic Politics and Technological Change in Local Government," Journal of Urban Analysis, 4(1):93118.

37. Levitan, Sar A., and Robert Taggart 1976. The Promise of Greatness, (Cambridge Massachusetts: Harvard University Press). 
38. Mazmanian, Daniel A., and Jeanne Nienaber 1979. Can Organizations Change? Environmental Protection, Citizen Participation, and the Corps of Engineers (Washington, D.C.: The Brookings Institution).

39. McLaughlin, Milbrey 1976. "Implementation as Mutual Adaptation," Teachers College Record, 77 (3), February.

40. Mechling, Jerry E. 1974. "A Successful Innovation: Manpower Scheduling," Urban Analysis, 3:259-313.

41. Merton, Robert K. 1968. "The Matthew Effect in Science," Science, 159:56-63, January.

42. Mohr, Lawrence 1978. "Process Theory and Variance Theory in Innovation Research," in Michael Radnor et al. (eds.), The Diffusion of Innovations: An Assessment (Evanston, minois: CIIST, Northwestern University, July).

43. Moore, Mark H., et al. 1974. "The Case of the Fourth Platoon," Urban Analysis, $3: 207-258$.

44. Murphy, Jerome T. 1971. "Title I of ESEA," Harvard Educational Review, 41:35-63, February.

45. Murphy, Jerome T. 1973. "Title V of ESEA: The Impact of Discretionary Funds on State Education Bureaucracies," Harvard Educational Review, 43:362-385, August.

46. Mytinger, Robert, 1968. Innovation in Local Health Services: A Study of the Adoption of New Programs by Local Health Departments (Washington, D.C.: U.S. Government Printing Office, February).

47. Nachmias, David 1978. "Assessing Program Accountability: Research Designs," in Scott Greer et al. (eds.), Accountability in Urban Society (Beverly Hills, Calif ornia: Sage Publications), pp. 249-272. '

48. Nelkin, Dorothy 1975. Methadone Maintenance: A Technological Fix (New York: George Braziller).

49. Nelson, Margaret, and Sam Sieber 1976. "Innovations in Urban Secondary Schools," School Review, 30:213-231, February.

50. Nelson, Richard R., and Douglas Yates (eds.) 1978. Innovation and Implementation in Public Organizations (Lexington, Massachusetts: Lexington Books).

51. Pressman, Jeffrey L., and Aaron Wildavsky 1973. Implementation (Berkeley: University of Calif ornia Press).

52. Public Affairs Counseling 1976. Factors Involved in the Transfer of Innovations: A Summary and Organization of the Literature (Washington, D.C.: U.S. Department of Housing and Urban Development).

53. Reiss, Albert J., Jr. 1971. "Systematic Observation of Natural Social Phenomena," in Herbert Costner (eds.), Sociological Methodology, 1971 (San Francisco: JosseyBass), pp. 3 -33.

54. Roessner, J. David, et al. 1979. Turning Laws into Incentives: The Implementation of State Solar Energy Initiatives (Golden, Colorado: Solar Energy Research Institute, February).

55. Rogers, Everett M. 1975. "Innovation in Organizations," paper presented at the American Political Science Association, San Francisco, September. 
56. Rogers, Everett M., with J. D. Eveland 1975. "Diffusion of Innovation Perspectives on National R\&D Assessment: Communication and Innovation in Organizations," in Patrick Kelly et al. (eds.), Technological Innovation (Atlanta: Georgia Institute of Technology, February), pp. 301-368.

57. Rogers, Everett M., and Rekha Agarwala-Rogers 1976. Communications in Organizations (New York: The Free Press).

58. Rothman, Jack 1974. Planning and Organizing for Social Change: Action Principles from Social Science (New York: Columbia University Press).

59. Sabatier, Paul 1978. "The Acquisition and Utilization of Technical Information by Administrative Agencies," Administrative Science Quarterly, 23:396-417, September.

60. Sanders, William B. (ed.) 1976. The Sociologist as Detective, 2nd ed. (New York: Praeger).

61. Selltiz, Claire, Lawrence S. Wrightsman, and Stuart W. Cook 1976. Research Methods in Social Relations, 3rd ed. (New York: Holt, Rinehart and Winston).

62. Stake, Robert E. 1978. "The Case Study Method in Social Inquiry," Educational Researcher, 7:5-8, February.

63. Stein, Harold (ed.) 1952. Public Administration and Policy Development (New York: Harcourt, Brace and World).

64. Walker, Warren E. 1975. "Applying Systems Analysis to the Fire Service," Fire Engineering, 128:38-64, August.

65. Walker, Warren E. 1978. Changing Fire Company Locations: Five Implementation Case Studies (Washington, D.C.: U.S. Department of Housing and. Urban Development, January).

66. Weick, Karl E. 1968. "Systematic Observational Methods," in Gardner Lindzey and Elliot Aronson (eds.), The Handbook of Social Psychology, 2nd. ed., Vol. II (Reading, Massachusetts: Addison-Wesley), pp. 357-451.

67. Williams, Walter 1976. "Implementation Analysis and Assessment," in Walter Williams and Richard F. Elmore (eds.), Social Program Implementation (New York: Academic Press), pp. 267-292.

68. Williams, Walter, and Richard F. Elmore (eds.) 1976. Social Program Implem entation (New York: Academic Press).

69. Yin, Robert K. 1972. Participant-Observation and the Development of Urban Neighborhood Policy (New York: The New York City-Rand Institute, February).

70. Yin, Robert K. 1977 a. "Evaluating Community Crime Prevention Programs," paper presented at the National Conference on Criminal Justice Evaluation, Washington, D.C., February.

71. Yin, Robert K. 1977b. "Production Efficiency vs. Bureaucratic Self-Interest: Two Innovative Processes?" Policy Sciences, 8:381-399, December.

72. Yin, Rober $\mathrm{K}$. 1978. "Are Traditional Research Designs Responsive?" in Scott Greer et al. (eds.), Accountability in Urban Society (Beverly Hills, California: Sage Publications), pp. 293-299.

73. Yin, Robert K. 1979. Changing Urban Bureaucracies: How New Practices Become Routinized (Lexington, Massachusetts: Lexington Books). 
74. Yin, Robert K., and Douglas Yates, 1975. Street-Level Governments (Lexington, Massachusetts: Lexington Books).

75. Yin, Robert K., et al. 1976. "The Difference that Quality Makes," Sociological Methods and Research, 5:139-156, November.

76. Zaltman, Gerald, et al. 1973. Innovations and Organizations (New York: Wiley and Sons). 


\begin{tabular}{|c|c|c|c|}
\hline $\begin{array}{c}\text { Document Control } \\
\text { Page }\end{array}$ & $\begin{array}{l}\text { 1. SERI Report No. } \\
\text { TR-352-57.7 }\end{array}$ & 2. NTIS Accession No. & 3. Recipient's Accession No. \\
\hline \multirow{2}{*}{\multicolumn{3}{|c|}{ Studying the Implementation of Public Programs }} & $\begin{array}{l}\text { 5. Publication Date } \\
\text { February } 1980 \\
\end{array}$ \\
\hline & & & \\
\hline \multicolumn{3}{|l|}{ 7. Author(s) } & 8. Pertorming Organization Rept. No. \\
\hline \multicolumn{2}{|c|}{$\begin{array}{l}\text { Robert } K \text {. Yin } \\
\text { 9. Performing Organization Name and Address }\end{array}$} & & $\begin{array}{l}\text { 10. ProjecuTask/Work Unit No. } \\
5633.98\end{array}$ \\
\hline \multicolumn{2}{|c|}{$\begin{array}{l}\text { Solar Energy Research Institute } \\
1617 \text { Cole Boulevard } \\
\text { Golden, Co }\end{array}$} & & $\begin{array}{l}\text { 11. Contract (C) or Grant (G) No. } \\
\text { (C) } \\
\text { (G) }\end{array}$ \\
\hline \multirow{2}{*}{\multicolumn{3}{|c|}{ 12. Sponsoring Organization Name and Address }} & $\begin{array}{c}\text { 13. Type of Report \& Period Covered } \\
\text { Technical Report }\end{array}$ \\
\hline & & & $\overline{14 .}$ \\
\hline
\end{tabular}

David Roessner - SERI Task Administrator

16. Abstract (Limit: 200 words) This report describes and critically assesses approaches that have been employed to study the implementation of public programs. Implementation is defined as the process by which new policies and/or practices are. installed in organ izations. The report was produced because of the increased interest among researcher \& policy makers alike in the linkages between policy \& outcome. The study of implementation has barely begun, \& it was recognized that methodological issues of a particularly complex nature arise because of certain unique characteristics of implementation processes: (1) they involve a series of decisions that occur over a long period of time, with no clear beginning or end points; (2) their outcomes have direct or indirect implications that are too complex for single-factor theories; (3) they involve a large number of participants; and (4) they involve situations that are rather unique in terms of agency context, historical moment in time, \& other key elements. The approach employed in the report was to examine the methods that have been used in a number of "exemplary" studies of implementation. These studies are commonly cited in publications \& informally in research circles. Descriptive materia from each study was used to address three questions: (1) How is evidence collected in studies of implementation? (2) How is evidence analyzed? (3) What are the reasons for believing the conclusions from such studes? The report concludes with recommendations for the conduct of future studies of implementation.

17. Document Analysis

a. Descriptors Implementation Stıdiea; Methodology; Analyuiv; Rcacarch

b. Identifiers/Open-Ended Terms

c. UC Categories

$58 b$

18. Availability Statement

National Technical Information Service

U. S. Department of Commerce

5285 Port Royal Road

Springfield, Virginia 22161

Form No. 8200-13 (6-79) 